\title{
Axillary Nodal Burden in Breast Cancer Patients With Pre-operative Fine Needle Aspiration-proven Positive Lymph Nodes Compared to Those With Positive Sentinel Nodes
}

\author{
CALOGERO CIPOLLA, MARIA ROSARIA VALERIO, NELLO GRASSI, SERGIO CALAMIA, \\ STEFANIA LATTERI, MARIO LATTERI, GIUSEPPA GRACEFFA and SALVATORE VIENI \\ University of Palermo, Department of Surgical Oncological and Oral Sciences, Palermo, Italy
}

\begin{abstract}
Background/Aim: Recent years have seen a considerable shift to a more conservative management of the axilla in patients with positive axillary sentinel lymph nodes. The aim of this study was to determine whether some breast cancer patients with a preoperative ultrasound-guided needle aspiration biopsy proven positive node could potentially be spared an axillary lymph node dissection according to the ACOSOG Z0011 trial criteria. Patients and Methods: A retrospective review was performed involving 623 breast cancer patients who underwent axillary lymph node dissection after either ultrasound-guided needle aspiration biopsy proven positive node or sentinel lymph node biopsy. Results: Patients with fine needle aspiration biopsy-proven positive node had worse prognosis and a higher nodal burden (6.7 vs 1.9 nodes, $p<0.001$ ), compared to those with positive sentinel lymph nodes. Conclusion: Patients with an ultrasound guided needle aspiration biopsy proven positive node are more likely to have tumor with more aggressive pathological characteristics and a higher nodal burden than those with a positive sentinel lymph node biopsy.
\end{abstract}

Despite the fact that knowledge on the molecular basis of breast cancer is increasingly growing, the axillary lymph node status still remains the most important prognostic factor in early breast cancer (1) and surgical management of the axilla continues to play an essential role in patients with invasive breast cancer.

This article is freely accessible online.

Correspondence to: Calogero Cipolla, Department of Surgical Oncological and Oral Sciences, University of Palermo, Via del Vespro 129, 90127 Palermo, Italy. Tel: +39 0916554520, Fax: +39 0916554429, e-mail: calogero.cipolla@unipa.it

Key Words: Breast cancer, axillary nodal burden, sentinel lymph node biopsy.
Sentinel lymph node biopsy (SLNB) represents nowadays the gold surgical technique to identify axillary metastases in clinically node-negative ( $\mathrm{cN} 0$ ) patients, showing equivalent outcomes compared to axillary lymph node dissection (ALND) $(2,3)$. On the other hand, ALND is still recommended to patients with metastasis in sentinel lymph nodes as well as to those who have been diagnosed with axillary lymph node metastases preoperatively $(2,3)$.

However, the involvement of axillary lymph nodes cannot be reliably determined preoperatively using clinical examination alone, and up to $45 \%$ of patients with clinically negative axilla have nodal metastases (4). For this reason, in the last decade, pre-operative ultrasound of the axilla is increasingly used to identify suspicious axillary nodes. Nevertheless, the sensitivity and specificity of ultrasound of the axilla are both moderate when the technique is used alone, but they increase considerably when combined with ultrasound-guided needle biopsy (USNB) (5-8). Patients with axillary lymph node metastases identified using USNB undergo ALND directly, avoiding a significant number of unnecessary $\operatorname{SLNB}(9,10)$.

During the last decade, the management of the axilla in breast cancer patients has been increasingly progressing towards a more conservative approach. In cases where SLNB is positive for isolated tumor cells and for micrometastases, ALND can be safely omitted because it does not improve survival (11-14). Furthermore, the ACOSOG Z0011 randomized trial has demonstrated no difference in the locoregional breast cancer recurrence or overall survival in women with cT1-T2 tumors and 1 to 2 positive sentinel node(s) who did not undergo completion ALND compared to control patients who received completion ALND (15-17).

An ongoing debate remains whether the findings of the ACOSOG Z0011 trial can be applied to patients with metastatic axillary disease identified using USNB. However, recent studies have shown that these patients have a high axillary nodal burden (18-20) and only a small number of them would satisfy the Z0011 trial criteria and safely avoid an axillary clearance. 
In the present study, we examined a large series of breast cancer patients who underwent ALND for metastatic axillary lymph nodes diagnosed both at preoperative USNB and at SLNB. The principal objective of the present study was to compare the axillary tumor burden in the two groups of patients. The second one was to quantify the proportion of patients with a USNB-positive axillary node who could potentially be spared ALND according to the ACOSOG Z0011 trial criteria and to identify any potential risk factors of extensive node burden.

\section{Patients and Methods}

After approval by the institutional review board at Department of Surgical Oncological and Oral Sciences, a retrospective analysis of the medical records of a large series of patients with histologically confirmed primary invasive breast cancer and positive axillary lymph node, diagnosed by either USNB or SLNB, was conducted. All patients were treated at our Division of Surgical Oncology from January 2010 through August 2019. Excluding criteria involve: i) patients with distant metastatic disease, ii) patients with recurrent disease, iii) patients who did not undergo ALND because of isolated tumor cells and micrometastases in sentinel lymph-nodes (SLN), iv) patients who received neoadjuvant chemotherapy.

In all patients, the preoperative diagnosis of infiltrating breast carcinoma was achieved by means of fine needle aspiration cytology and/or by percutaneous core biopsy of the breast lesions, under stereotactic or ultrasound control. Axillary staging was made by means of both clinical and ultrasonography examination. If suspicious axillary nodes where discovered, they were biopsied using USNB. Criteria to define suspicious lymph nodes included: i) cortical thickness $\geq 3 \mathrm{~mm}$, ii) focal or eccentric cortical thickening and iii) an abnormal or absent clear hilum.

SLN was localized using subdermal periareolar injection of technetium-labeled human albumin performed the day before the surgery. For the intraoperative identification of the SLN, a radioguided surgical probe was used. In the few cases where the radioguided surgical probe picked up a weak radiotracer signal, about 10 min before the beginning of surgery, a subdermal periareolar injection of $0.5-0.8 \mathrm{ml}$ of vital stain ( $1 \%$ isosulfan blue) was performed.

ALND included for each patient the dissection of all three levels of axillary lymph nodes. The total number of nodes removed, the number of positive nodes and the presence or absence of extranodal extensions were recorded. Within the SLNB cohort of patients, the total number of nodes removed was defined as the number of SLNs excised in addition to the total number of nodes removed during the subsequent ALND.

Patient demographics, tumor size, tumor histology, tumor grade, tumor multicentricity, hormone receptor subtype, Ki-67 proliferation index (a Ki-67 positive in more than $20 \%$ of the cell population was considered as a high proliferation index), HER-2 status, number of positive nodes and presence or absence of extranodal invasion were recorded.

The main tumor diameter was macroscopically measured on the surgical resected specimen of the primary tumor and it was confirmed at the microscopical observation. The histological grade was assessed by using the Elston and Ellis score system (21). HER2 status was evaluated by IHC immunostaining on $3-\mu \mathrm{m}$ thick sections that were mounted on silane-coated slides using
Table I. Patient demographics and tumour characteristics.

\begin{tabular}{|c|c|c|c|}
\hline & $\begin{array}{l}\text { Positive at USNB } \\
\qquad(\mathrm{n}=347)\end{array}$ & $\begin{array}{l}\text { Positive at SLNB } \\
\qquad(\mathrm{n}=276)\end{array}$ & $p$-Value \\
\hline Mean age & $\begin{array}{c}64.5 \\
\text { (range }=39-81)\end{array}$ & $\begin{array}{c}54.6 \\
\text { (range }=37-79)\end{array}$ & 0.015 \\
\hline Tumour size (mm) & & & 0.002 \\
\hline$\leq 20 \mathrm{~mm}$ & $74(21.3)$ & $105(38.1)$ & \\
\hline $20.1-50 \mathrm{~mm}$ & $218(62.8)$ & $143(51.8)$ & \\
\hline$>50 \mathrm{~mm}$ & $55(15.8)$ & $28(10.1)$ & \\
\hline Histological type & & & 0.251 \\
\hline Ductal infiltrating & $225(64.8)$ & 199 (72.1) & \\
\hline Lobular infiltrating & $54(15.6)$ & $36(13.1)$ & \\
\hline Other & $68(19.6)$ & $41(14.8)$ & \\
\hline Tumour grade & & & 0.005 \\
\hline Median & G3 & G2 & \\
\hline G1 & 17 (4.9) & $28(10.1)$ & \\
\hline G2 & $118(34.1)$ & $131(47.4)$ & \\
\hline G3 & $208(59.9)$ & $117(42.4)$ & \\
\hline Unknown & $4(1.1)$ & & \\
\hline Multicentricity & & & 0.525 \\
\hline Yes & $73(21.0)$ & 65 (23.6) & \\
\hline No & $274(79.0)$ & $211(76.4)$ & \\
\hline Lymphovascular invasion & & & 0.810 \\
\hline Yes & $211(60.8)$ & $171(61.9)$ & \\
\hline No & $136(39.2)$ & $105(38.1)$ & \\
\hline Estrogen receptor status & & & 0.001 \\
\hline Positive & $258(74.4)$ & $251(90.1)$ & \\
\hline Negative & $83(23.9)$ & $25(9.0)$ & \\
\hline Unknown & $6(1.7)$ & & \\
\hline Ki-67 & & & 0.001 \\
\hline$>20 \%$ & $261(75.2)$ & $25(9.0)$ & \\
\hline$<20 \%$ & $75(21.6)$ & $246(89.1)$ & \\
\hline Unknown & $11(3.2)$ & $5(1.8)$ & \\
\hline HER-2 status & & & 0.015 \\
\hline Positive & $101(29.1)$ & $49(17.8)$ & \\
\hline Negative & $236(68.0)$ & $221(80.1)$ & \\
\hline Unknown & $10(2.9)$ & $6(2.2)$ & \\
\hline
\end{tabular}

HercepTest $^{\mathrm{TM}}$ (Dako, Glostrup, Denmark). An antigen retrieval pretreatment was performed by three changes in $0.01 \mathrm{M}$ citrate buffer (pH 6.0) in a microwave oven at $750 \mathrm{~W}$. Each immunostained section was evaluated according to the ASCO/CAP 2018 Guidelines for breast cancer (22). All the cases that were considered equivocal (2+) were further assessed using the FISH test (pharmDx; Dako) in three reference laboratories. Gene amplification was recorded when the HER2:CEP17 signal ratio was $>2.0$.

In parallel sections that were obtained from the same tissue blocks, Ki-67 antigen was unmasked by the previously cited retrieval procedure. Ki-67 antiserum (clone MIB-1; w.d. 1:50; Dako) was applied for $30 \mathrm{~min}$ at room temperature. The Ki-67 labeling index (LI) was calculated as the mean percentage by counting the stained nuclei of 1,000 tumor cells in three representative neoplastic fields. All degrees of nuclear staining intensity were taken into consideration. The median Ki-67 LI value (30\%) was utilized as the cut-off point to define low and high Ki-67 expression.

Differences between the two groups were assessed using the $\chi^{2}$ test, Fisher's exact test and the Mann-Whitney $U$-test, where appropriate. Values were considered statistically significant when $p<0.05$. 
Table II. Pathology findings in SLNB-positive patients.

\begin{tabular}{lc}
\hline & Mean number (range) \\
\hline SLNs removed & $3.1(1-5)$ \\
Positive SLNs & $1.7(1-3)$ \\
Lymph nodes excised at ALND & $15(7-26)$ \\
Metastatic lymph nodes at ALND & $2.3(0-9)$ \\
\hline & Number $(\%)$ \\
\hline Macrometastases & \\
1 lymph node & $121(43.8)$ \\
2 lymph nodes & $59(21.4)$ \\
$\geq 3$ lymph nodes & $96(34.8)$ \\
Extranodal invasion & \\
Present & $86(31.1)$ \\
Absent & $185(67.1)$ \\
Unknown & $5(1.8)$ \\
\hline
\end{tabular}

SLNB: Sentinel lymph node biopsy; SLNs: sentinel lymph nodes; ALND: axillary lymph node dissection.

\section{Results}

Our institutional breast cancer registry contained records for 1194 patients with invasive breast carcinoma treated from January 2010 to August 2019. A total of 623 patients who underwent preoperative axillary ultrasonography examination were eligible for inclusion in the study. Among these, 347 (55.7\%) proceeded to ALND after a USNB-proven positive axillary lymph node, whereas $276(44.3 \%)$, were confirmed for ALND after a positive SLNB. Patient demographics and tumor characteristics, summarized in Table I, show that the women in the USNB-positive group were significantly older compared to those of SLNB-positive group $(p=0.015)$. A comparison of pathological characteristics between the two groups revealed that the patients in USNB-positive group had worse prognostic factors, presenting larger tumors $(p=0.002)$ with a higher tumor grade $(p=0.005)$, compared to those of the SLNB-positive group. Similarly, the proportion of negative estrogen receptors $(p=0.001)$, HER-2 positive $(p=0.015)$ and Ki-67 positive in more than $20 \%$ of the cell population ( $p=0.001)$ were greater in patients of the USNB-positive group compared to the SLNB-positive group. Ductal infiltrating carcinoma was the most common histological type in both groups of patients $(p=0.251)$. Lymphovascular invasion, although more prominent in the USNB-positive group, did not reach statistical significance $(p=0.810)$.

Pathological findings in the SLNB-positive group are summarized in Table II. The mean number of removed SLNs was 3.1 (range=1-5), more than $65 \%$ of the patients had 1 or 2 positive SLN and about $30 \%$ presented extranodal extension.

The mean number of lymph nodes excised at ALND was 19.2 (range=7-39) in the USBN-positive group and 17.1
Table III. Axillary nodes excised at ALND and positive nodal burden.

\begin{tabular}{lccc}
\hline & $\begin{array}{c}\text { Positive at } \\
\text { USNB } \\
(\mathrm{n}=347)\end{array}$ & $\begin{array}{c}\text { Positive at } \\
\text { SLNB } \\
(\mathrm{n}=276)\end{array}$ & $p$-Value \\
\hline Mean number of excised nodes & 19.2 & 17.1 & 0.35 \\
Range & $7-39$ & $8-26$ & \\
Mean number of positive nodes & 6.7 & 1.7 & $<0.001$ \\
Range & $2-21$ & $1-9$ & \\
Number of positive nodes & & & $<0.001$ \\
& Number (\%) & Number (\%) & \\
1 & $61(17.6)$ & $121(43.8)$ & \\
2 & $83(23.9)$ & $59(21.4)$ & \\
3 & $39(11.2)$ & $37(13.4)$ & \\
$\geq 4$ & $164(47.2)$ & $59(21.4)$ & \\
Extranodal invasion & & \multicolumn{2}{c}{$<0.001$} \\
Present & $223(64.2)$ & $97(35.1)$ & \\
Absent & $124(35.8)$ & $179(64.9)$ & \\
\hline
\end{tabular}

SLNB: Sentinel lymph node biopsy; USNB: ultrasound-guided needle biopsy; ALND: axillary lymph node dissection.

(range=8-26) in the SLNB-positive group, with no statistical significance. Instead, a high statistical significance $(p<0.001)$ was registered with regard to the mean number of positive nodes: 6.7 (range $=2-21)$ in the USBN vs. 1.7 (range $=1-9)$ in the SLNB-positive group. Moreover, in the USNB-positive group the number of patients with 4 or more positive nodes and with extranodal invasion was significantly higher $(p<0.001)$, compared to the patients of the SLNB-positive group (Table III). Nonetheless, it is worth noting how a large number of patients (41.5\%) in the USNB-positive group had 1 to 2 positive axillary lymph nodes, meeting the ACOSOG Z0011 criteria to avoid an unnecessary ALND.

Table IV reports the correlation between the tumor characteristics and the number of positive axillary lymph nodes in USNB-positive group. Following the ACOSOG Z0011 trial criteria, each of the characteristics was compared between the two subgroups of patients, those with 1 to 2 positive nodes and those with 3 or more positive nodes. Finally, potential predictors of extensive axillary tumor burden were: i) a Ki-67 proliferation index positive in more than $20 \%$ of the cell population and ii) a tumor diameter larger than $50 \mathrm{~mm}$.

\section{Discussion}

The surgical management of the axilla in early stage breast cancer patients has evolved quickly in recent years with the goal of avoiding overtreatment to reduce morbidity and at same time ensuring the oncological safety. The AMAROS trial showed that axillary lymph node dissection and axillary radiotherapy in patients with one positive sentinel node provide excellent and comparable axillary control for T1-2 primary breast cancer and no palpable lymphadenopathy, and that 
Table IV. Correlations between tumour characteristics and number of positive nodes in the USNB-positive group.

\begin{tabular}{|c|c|c|c|}
\hline \multirow[b]{2}{*}{ Mean age } & \multicolumn{2}{|c|}{$\begin{array}{c}\text { Number of positive axillary } \\
\text { lymph nodes }\end{array}$} & \multirow[b]{2}{*}{$p$-Value } \\
\hline & $\begin{array}{c}1-2 \\
(\mathrm{n}=144)\end{array}$ & $\begin{array}{c}\geq 3 \\
(\mathrm{n}=203)\end{array}$ & \\
\hline Tumour size (mm) & & & $<0.001$ \\
\hline$\leq 20 \mathrm{~mm}$ & $42(29.1)$ & $32(15.7)$ & \\
\hline $20.1-50 \mathrm{~mm}$ & $89(61.8)$ & $129(63.5)$ & \\
\hline$>50 \mathrm{~mm}$ & $13(9.0)$ & $42(20.7)$ & \\
\hline Histological type & & & 0.485 \\
\hline Ductal infiltrating & $96(66.7)$ & $129(63.5)$ & \\
\hline Lobular infiltrating & $21(14.6)$ & $33(16.2)$ & \\
\hline Other & $27(18.7)$ & $41(20.2)$ & \\
\hline Tumour grade & & & 0.453 \\
\hline G1 & $12(8.3)$ & $5(2.5)$ & \\
\hline $\mathrm{G} 2$ & $49(34.0)$ & $69(33.9)$ & \\
\hline G3 & $82(56.9)$ & $126(62.1)$ & \\
\hline Unknown & $1(0.7)$ & $3(1.5)$ & \\
\hline Multicentricity & & & 0.120 \\
\hline Yes & $30(20.8)$ & $43(21.2)$ & \\
\hline No & $114(79.2)$ & $160(78.8)$ & \\
\hline Lymphovascular invasion & & & 0.567 \\
\hline Yes & $83(57.6)$ & $128(63.1)$ & \\
\hline No & $61(42.4)$ & $75(36.9)$ & \\
\hline Estrogen receptor status & & & 0.410 \\
\hline Positive & $106(73.6)$ & $152(74.9)$ & \\
\hline Negative & $34(23.7)$ & $49(24.1)$ & \\
\hline Unknown & $4(2.8)$ & $2(0.98)$ & \\
\hline Ki-67 & & & $<0.001$ \\
\hline$>20 \%$ & $96(66.7)$ & $165(81.3)$ & \\
\hline$<20 \%$ & $44(30.5)$ & $31(15.3)$ & \\
\hline Unknown & $4(2.8)$ & $7(3.4)$ & \\
\hline HER-2 status & & & 0.551 \\
\hline Positive & $46(31.9)$ & $55(27.1)$ & \\
\hline Negative & $94(65.3)$ & $142(69.9)$ & \\
\hline Unknown & $4(2.8)$ & $6(2.9)$ & \\
\hline
\end{tabular}

USNB: Ultrasound-guided needle biopsy.

axillary radiotherapy results in significantly less morbidity compared to surgery (23). Moreover, results from the ASOCOG Z0011 trial, suggested that ALND can be safely omitted in selected patients with cT1-T2, cN0 primary breast cancer and 1 to 2 positive sentinel lymph nodes who underwent breast conservative surgery, whole breast radiotherapy and systemic therapy (15-17). Subsequently, in a publication of results from patients who fulfill the Z0011 criteria, the rates of ALND showed a statistically significant decrease from 2010 (89\%) to 2011 (73\%), reaching $46 \%$ in 2016 (24).

However, an ongoing debate remains whether the Z0011 trial criteria can also be applied in some patients with a preoperative USNB-positive axillary lymph node. Boland $e t$ al. $(18,24)$, have argued that these patients should undergo an ALND, provided that they have a high nodal burden and may not be Z0011 eligible. In addition, in this category of patients, Verheuvel et al. (20) have found a more intense extranodal invasion and worse disease-free survival rates compared to those with positive SLNB. However, other studies (25-27) have found that about half of positive USNB patients could be treated safely with axillary preservation according to the Z0011 trial criteria.

In accordance with previous data $(18,20,24)$, the present study confirms that patients with USNB-positive axillary lymph nodes have a higher nodal burden of disease compared to those with a positive SLNB. The mean number of positive nodes excised at ALND was of 6.7 in the USNB-positive cohort compared to just 1.7 in the SLNB group. Moreover, about $60 \%$ of patients in USNB-positive cohort had 3 or more positive lymph nodes compared to less than $35 \%$ found in the SLNB positive cohort. Likewise, an extranodal invasion was present in more than $64 \%$ of patients in the USNB-positive group compared to about $35 \%$ in the SLNB group.

This last finding could be related to the more aggressive tumor characteristics highlighted in the USNB-positive patients. In accordance with what has been reported in other studies $(20,24,26)$, in the present study this cohort of patients had more aggressive tumor characteristics as well. Larger tumor size, estrogens receptor negativity, HER-2 amplification, high Ki-67 proliferation index, high histological grade and extranodal invasion were significantly higher when compared to the SLNB-positive group. It is possible that the more aggressive biology of the tumor determining its propensity to have a higher nodal metastatic burden, can also be the reason for an increased probability of being detected by the ultrasound of the axilla.

Nonetheless, in this study $41.5 \%$ of the USNB-positive patients (144/347 patients) had 1 to 2 metastatic axillary lymph nodes. Therefore, according to the ASOCOG Z0011 trial results, in these patients ALND did not produce any further benefit. The question still remains as to what are the criteria to identify this subgroup of patients that could avoid ALND and undergo SLNB.

This study showed that a larger tumor size and a higher Ki67 proliferation index could potentially be used as predictive factors of a high nodal burden. Lloyd et al. (26) have reported that the combination between tumor size and tumor histology have a high sensitivity (89\%) and a high positive predictive value $(63 \%)$ to forecast a higher nodal burden in USNBpositive patients. Similarly, Pilewskie et al. (25) have reported that tumor histology and lympho-vascular invasion were statistically significant predictive factors of an extensive nodal involvement. However, the same group of authors has published three additional papers stating that histological features of the tumor were not predictive for an elective ALND (28-30), in accordance with the study by Lim et al. (27) who, recently, did not find any significant preoperative clinical or histological predictive factors linked to a higher nodal burden. 
In the same paper the authors have reported that patients with a high nodal burden were more likely to have $\geq 3$ ultrasounddetected abnormal lymph nodes $(p<0.0001)$ and maximum cortical thickness $>4 \mathrm{~mm}(p=0.0036)$, concluding that the detection of $\geq 3$ abnormal lymph nodes in axillary sonography was the most predictive factor of high nodal burden.

Despite the fact that this study has some limitations mainly due to its retrospective nature and single centre data collection and reporting, in accordance to many other studies, it showed that breast cancer patients with preoperative USNB-proven positive axillary nodes have a higher axillary nodal burden compared to those with SLNBdetected metastases and for this reason they are likely to require an elective ALND avoiding unnecessary SLNB. Nevertheless, a consistent proportion of these patients (around the $41 \%$ in this study) had 1 to 2 positive axillary lymph nodes, meeting the ACOSOG Z0011 criteria and were thus over-treated by ALND. Unfortunately, to date, there are not enough valid criteria to identify this cohort of patients.

Considering that the detection of $\geq 3$ abnormal lymph nodes using the axillary sonography could be considered as a valid predictive factor of high nodal burden, an improvement in ultrasound technology and radiologists' experience are needed to tailor axillary treatment in patients with USNB-positive axillary nodes, so that the ones selected can safely avoid ALND.

\section{Conflicts of Interest}

The Authors declare that they have no competing interests.

\section{Authors' Contributions}

CC, MRV, GG and SV were involved with study conception and design, analysis and interpretation of data, drafting of manuscript as well as critical revision of manuscript.

$\mathrm{NG}, \mathrm{SC}$, SL were involved with acquisition and analysis of data, drafting and revision of manuscript. ML was involved with study conception and design as well as critical revision of manuscript. All Authors read and approved the final version of the manuscript.

\section{References}

1 Quan ML and McCready D: The evolution of lymph node assessment in breast cancer. J Surg Oncol 99: 194-198, 2009. PMID: 19021226 . DOI: $10.1002 /$ jso.21201

2 Veronesi U, Viale G, Paganelli G, Zurrida S, Luini A, Galimberti V, Veronesi P, Intra M, Maisonneuve P, Zucca F, Gatti G, Mazzarol G, De Cicco C and Vezzoli D: Sentinel lymph node biopsy in breast cancer: 10-year results of a randomized controlled study. Ann Surg 251: 595-600, 2010. PMID: 20195151. DOI: 10.1097/SLA.0b013e3181c0e92a

3 Krag DN, Anderson SJ, Julian TB, Brown AM, Harlow ST, Costantino JP, Ashikaga T, Weaver DL, Mamounas EP, Jalovec LM, Frazier TG, Noves RD, Robidoux A, Scarth HM and Wolmark $\mathrm{N}$ : Sentinel-lymph-node resection compared with conventional axillary-lymph-node dissection in clinically node-negative patients with breast cancer: overall survival findings from the NSABP B32 randomised phase 3 trial. Lancet Oncol 11: 927-933, 2010. PMID: 28063759. DOI: 10.1016/S1470-2045(10)70207-2

4 de Freitas R Jr, Costa MV, Schneider SV, Nicolau MA and Marussi E: Accuracy of ultrasound and clinical examination in the diagnosis of axillary lymph node metastases in breast cancer. Eur J Surg Oncol 17: 240-244, 1991. PMID: 2044777.

5 Houssami N, Ciatto S, Turner RM, Cody HS $3^{\text {rd }}$ and Macaskill P: Preoperative ultrasound-guided needle biopsy of axillary nodes in invasive breast cancer: meta-analysis of its accuracy and utility in staging the axilla. Ann Surg 254: 243-251, 2011. PMID: 21597359. DOI: 10.1097/SLA.0b013e31821f1564

6 Diepstraten SCE, Sever AR, Buckens CFM, Veldhuis WB, van Dalen T, van den Bosch MA, Mali WP and Verkooijen HM: Value of preoperative ultrasound-guided axillary lymph node biopsy for preventing completion axillary lymph node dissection in breast cancer: a systematic review and meta-analysis. Ann Surg Oncol 21: 51-59, 2014. PMID: 24008555. DOI: 10.1245/s 10434-013-3229-6

7 Park SH, Kim MJ, Park BW, Moon HJ, Kwak JY and Kim EK: Impact of preoperative ultrasonography and fine-needle aspiration of axillary lymph nodes on surgical management of primary breast cancer. Ann Surg Oncol 18: 738-744, 2011. PMID: 20890729. DOI: 10.1245/s10434-010-1347-y

8 Topal U, Punar S, Tasdelen I and Adim SB: Role of ultrasoundguided core needle biopsy of axillary lymph nodes in the initial staging of breast carcinoma. Eur J Radiol 56: 382-385, 2005. PMID: 16024205. DOI: 10.1016/j.ejrad.2005.05.018

9 de Kanter AY, van Eijck CH, van Geel AN, Kruijt MH, Henzen SC, Paul MA, Eggermont AM and Wiggers T: Multicentre study of ultrasonographically guided axillary node biopsy in patients with breast cancer. Br J Surg 86: 1459-1462, 1999. PMID: 10583296. DOI: 10.1046/j.1365-2168.1999.01243.x

10 Kuenen-Boumeester V, Menke-Pluymers M, de Kanter AY, Obdejin IM, Urich D and Van Der Kwast TH: Ultrasound-guided fine needle aspiration cytology of axillary lymph nodes in breast cancer patients. A preoperative staging procedure. Eur J Cancer 39: 170-174, 2003. PMID: 12509948. DOI: 10.1016/s09598049(02)00501-4

11 Galimberti V, Cole BF, Zurrida S, Viale G, Luini A, Veronesi P, Baratella P, Chifu C, Sargenti M, Intra M, Gentilini O, Mastropasqua MG, Mazzarol G, Massarut S, Garbay JR, Zgajnar J, Galatius H, Recalcati A, Littlejohn D, Bamert M, Colleoni M, Price KN, Regan MM, Goldhirsch A, Coates AS, Gelber RD, Veronesi $U$ and International Breast Cancer Study Group Trial 23-01 investigators: Axillary dissection versus no axillary dissection in patients with sentinel-node micrometastases (IBCSG 23-01): a phase 3 randomised controlled trial. Lancet Oncol 14: 297-305, 2013. PMID: 23491275. DOI: 10.1016/ S1470-2045(13)70035-4

12 Sola M, Alberro JA, Fraile M, Santesteban P, Ramos M, Fabregas R, Moral A, Ballester B and Vidal S: Complete axillary lymph node dissection versus clinical follow-up in breast cancer patients with sentinel node micrometastasis: final results from the multicenter clinical trial AATRM 048/13/2000. Ann Surg Oncol 20: 120-127, 2013. PMID: 22956062. DOI: 10.1245/ s10434-012-2569-y

13 Cipolla C, Graceffa G, Latteri S, Marino MV, Latteri M and Vieni S: Completion axillary lymph node dissection can be avoided in patients 
with invasive breast cancer and sentinel lymph node micrometastases Ann Ital Chir 89: 107-112, 2018. PMID: 29134959.

14 Cipolla C, Graceffa G, La Mendola R, Fricano S, Fricano M and Vieni S: The prognostic value of sentinel lymph node micrometastases in patients with invasive breast carcinoma Ann Ital Chir 86: 497-502, 2015. PMID: 26898168.

15 Giuliano AE, Hunt KK, Ballman KV, Beitsch PD, Withworth PW, Blumencranz PW, Leitch AM, Saha S, McCall LM and Morrow M: Axillary dissection vs no axillary dissection in women with invasive breast cancer and sentinel node metastasis: a randomized clinical trial. JAMA 305: 569-575, 2011. PMID: 21304082. DOI: $10.1001 /$ jama.2011.90

16 Giuliano AE, Ballman K, McCall L, Beitsch P, Withworth PW, Blumencranz P, Leitch AM, Saha S, Morrow M and Hunt KK: Locoregional recurrence after sentinel lymph node dissection with or without axillary dissection in patients with sentinel lymph node metastases: long-term follow-up from the American College of Surgeons Oncology Group (Alliance) ACOSOG Z0011 Randomized Trial. Ann Surg 252: 413-420, 2016. PMID: 27513155. DOI: 10.1097/SLA.0000000000001863

17 Giuliano AE, McCall L, Beitsch P, Withworth PW, Blumencranz P, Leitch AM, Saha S, Hunt KK, Morrow M and Ballmann K: Locoregional recurrence after sentinel lymph node dissection with or without axillary dissection in patients with sentinel lymph node metastases: The American College of Surgeons Oncology Group Z0011 randomized trial. Ann Surg 252: 426-432, 2010. PMID: 20739842. DOI: 10.1097/SLA.0b013e3181f08f32

18 Boland MR, Prichard RS, Daskalova I, Lowery AJ, Evoy D, Geraghty J, Rothwell J, Quinn CM, O'Doherty A and McDermott EW: Axillary nodal burden in primary breast cancer patients with positive pre-operative ultrasound guided fine needle aspiration cytology: management in the era of ACOSOG Z011. Eur J Surg Oncol 41: 559-565, 2015. PMID: 25648466. DOI: 10.1016/j.ejso.2015.01.011

19 Cools-Lartigue J, Sinclair A, Trabulsi N, Meguerditchian A, Mesurolle B, Fuhrer R and Materissian S: Preoperative axillary ultrasound and fine-needle aspiration biopsy in the diagnosis of axillary metastases in patients with breast cancer: predictors of accuracy and future implications. Ann Surg Oncol 20: 819-827, 2013. PMID: 22972506. DOI: 10.1245/s10434-012-2609-7

20 Verheuvel NC, van den Hoven I, Ooms HW, Voogd AC and Roumen RM: The role of ultrasound-guided lymph node biopsy in axillary staging of invasive breast cancer in the postACOSOG Z0011 trial era. Ann Surg Oncol 22: 409-415, 2015. PMID: 25205303. DOI: 10.1245/s10434-014-4071-1

21 Wolff AC, Hammond MEH, Allison KH, Harvey BE, Mangu PB, Bartlett JMS, Bilous M, Ellis IO, Fitzgibbons P, Hanna W, Jenkins RB, Press MF, Spears PA, Vance GH, Viale G, McShane LM, and Dowsett M: Human epidermal growth factor receptor 2 testing in breast cancer: American Society of Clinical Oncology/College of American Pathologists Clinical Practice Guideline Focused Update. J Clin Oncol 36(20): 2105-2122, 2018. PMID: 29846122. DOI: $10.1200 /$ JCO.2018.77.8738

22 Elston CW and Ellis IO: Pathological prognostic factors in breast cancer. I. The value of histological grade in breast cancer: experience from a large study with long-term follow-up. Histopathology 19(5): 403-410, 1991. PMID: 1757079. DOI: 10.1111/j.1365-2559.1991.tb00229.x

23 Donker M, van Tienhoven G, Straver ME, Meijnen P, van de Velde CJ, Mansel RE Cataliotti L, Westenberg AH, Klinkenbijl
JH, Orzalesi L, Bouma WH, van der Mijle HC, Nieuwenhuijzen GA, Veltkamp SC, Slaets L, Duez NJ, de Graaf PW, van Dalen T, Marinelli A, Rijna H, Snoj M, Bundred NJ, Merkus JW, Belkacemi Y, Petignat P, Schinagl DA, Coens C, Messina CG, Bogaerts J and Rutgers EJ: Radiotherapy or surgery of the axilla after a positive sentinel node in breast cancer (EORTC 1098122023 AMAROS): a randomised, multicentre, open-label, phase 3 non-inferiority trial. Lancet Oncol 15: 1303-1310, 2014. PMID: 25438688. DOI: 10.1016/S1470-2045(14)70460-7

24 Boland MR, Ni Cearbhail R, Fitzpatrick K, Walsh SM, Evoy D, Geraghty J, Rothwell J, McNally S, O'Doherty A, Quinn CM, McDermott EW and Prichard RS: A positive node on ultrasound-guided fine needle aspiration predicts higher nodal burden than a positive sentinel lymph node biopsy in breast carcinoma. World J Surg 40: 2157-2162, 2016. PMID: 27206399. DOI: $10.1007 / \mathrm{s} 00268-016-3557-3$

25 Pilewskie M, Mautner SK, Stempel M, Eaton A and Morrow M: Does a positive axillary lymph node needle biopsy result predict the need for an axillary lymph node dissection in clinically nodenegative breast cancer patients in the ACOSOG Z0011 era? Ann Surg Oncol 23: 1123-1128, 2016. PMID: 26553439. DOI: 10.1245/s 10434-015-4944-y

26 Lloyd P, Theophilidou E, Newcombe RG, Pugh L and Goyal A: Axillary tumour burden in women with a fine-needle aspiration/core biopsy-proven positive node on ultrasonography compared to women with a positive sentinel node. Br J Surg 104: 1811-1815, 2017. PMID: 28991362. DOI: 10.1002/bjs.10661

27 Lim GH, Upadhyaya VS, Acosta HA, Lim JMA, Allen JC Jr and Leong LCH: Preoperative predictors of high and low axillary nodal burden in Z0011 eligible breast cancer patients with a positive lymph node needle biopsy result. Eur J Surg Oncol 44: 945-950, 2018. PMID: 29705286. DOI: 10.1016/j.ejso. 2018.04 .003

28 Dengel LT, Van Zee KJ, King TA, Stempel M, Cody HS, ElTamer M, Gemignani ML, Sclafani LM, Sacchini VS, Heerdt AS, Plitas G, Junqueira M, Capko D, Patil S and Morrow M: Axillary dissection can be avoided in the majority of clinically node-negative patients undergoing breast-conserving therapy. Ann Surg Oncol 21: 22-27, 2014. PMID: 23975314. DOI: 10.1245/s 10434-013-3200-6

29 Mamtani A, Patil S, Van Zee KJ, Codi HS3rd, Pilevskie M, Barrio AV, Heerdt AS and Morrow M: Age and receptor status do not indicate the need for axillary dissection in patients with sentinel lymph node metastases. Ann Surg Oncol 23: 3481-3486, 2016. PMID: 27169771. DOI: 10.1245/s10434-016-5259-3

30 Morrow M, Van Zee KJ, Patil S, Petruolo O, Mamtani A, Barrio AV, Capko D, El-Tamer M, Gemignani ML, Heerdt AS, Kirstein L, Pilewskie M, Plitas G, Sacchini VS, Sclafani LM, Ho A and Cody HS: Axillary dissection and nodal irradiation can be avoided for most node-positive Z0011-eligible breast cancers: a prospective validation study of 793 patients. Ann Surg 266: 457-462, 2017. PMID: 28650355. DOI: 10.1097/SLA. 0000000000002354 